\title{
Compare the model of Iran national quality award and the EFQM model
}

\author{
Saleh Mojdehi \\ (General Office of Standards and Industrial Research of Sistan and Baluchestan Province of Iran, Zahedan 9816816389, Iran)
}

\begin{abstract}
Nowadays, there are a lot of challenges for global processing in countries economic companies. One of the important reasons is lack of changes that must be with world-class technology for making a competition in industry, and another important reason is lack of organized distinction for managers. Most of high rank managers don't have good points for charging and worry about it. In this essay, there have been excellence organized model of EFQM and Iran national quality award which are compared by a case study, and finally, it has suggested using a native model.
\end{abstract}

Key words: model of Iran national quality award; EFQM; self-evaluation

\section{Introduction}

Evaluating of action and situation of present organizations and recognize of promotion field for being in environment which are more competitive everyday need to make a organized framework for analyzing different reasons in an active relationship, and it should evaluate with environment situation.

There are many ways for evaluating action of organizations, which have benefits and risks for themselves. If it can have the same method between different companies and organizations, it may make a relative comparison for them. Evaluating of actions with traditional methods contrast to accept the continuous promotion ideas, usage is hard in action, flexibility is in low level, don't notice the customer necessaries and don't able to mix with organization's strategy (Wongrassamee, 2003).

The organizations evaluating models answer these questions: What is the perfect organization? What purposes and subjects study? What is their outlook? How about the future? What are values on their behavior and what have standards for testing? Every one of the above contents can make many windows for basic changing in organizations, and promoting their actions (Khalili, 2005). If the companies can not relate organization excellence models, because of research orders and world experiments condemned to distraction. Moreover, the Europeans model of EFQM has more commonality at the world, and it is a sample for a lot of countries for planning national awards.

Whereas, the Standard and Industrial Research General Office of Sistan and Baluchestan Province is one of the biggest office in Iran, and the most volume of imports and exports relate to it, their services are very important, and it need to notice to districts for improving the quality of services. Anyway, there is a question which does the action of standard and research general office in Sistan and Baluchestan is match with organization evaluation model of EFQM? And do the research of evaluating are the same to results of model of Iran national quality award?

Saleh Mojdehi, Master of science in industrial engineering, General Office of Standards and Industrial Research of Sistan and Baluchestan Province of Iran; research field: industrial engineering. 


\section{The perfect model or organization excellence of EFQM}

In resent years, there have been many efforts to find standard or framework that the organizations use it for evaluating themselves. By recognition of these challenges, the foundation of Europeans quality management made. This foundation has a basic role to persuade and help European companies for developing European quality of management. The Europeans companies accept that the total quality management is the way for managing actions to get efficiency, impression and competitive performances. It guarantees the success in long time with ensuring customers, staff necessaries and other beneficiaries of organization.

The perfect model of EFQM has introduced as first framework for evaluating and promoting organizations. With this model, the organizations can evaluate success rate in performance of their promotion programs in different level of time. It also can compare their actions with another organization, special with best ones.

As shown in Fig. 1, this model has 9 parameters, 5 of which (leadership, human resources, strategy, trade partners and resources, and process) are strength, and have 500 point. Another 4 parameters (result of human resource, customers, social and key result of action) named result and have 500 point (Carlos, 2003).

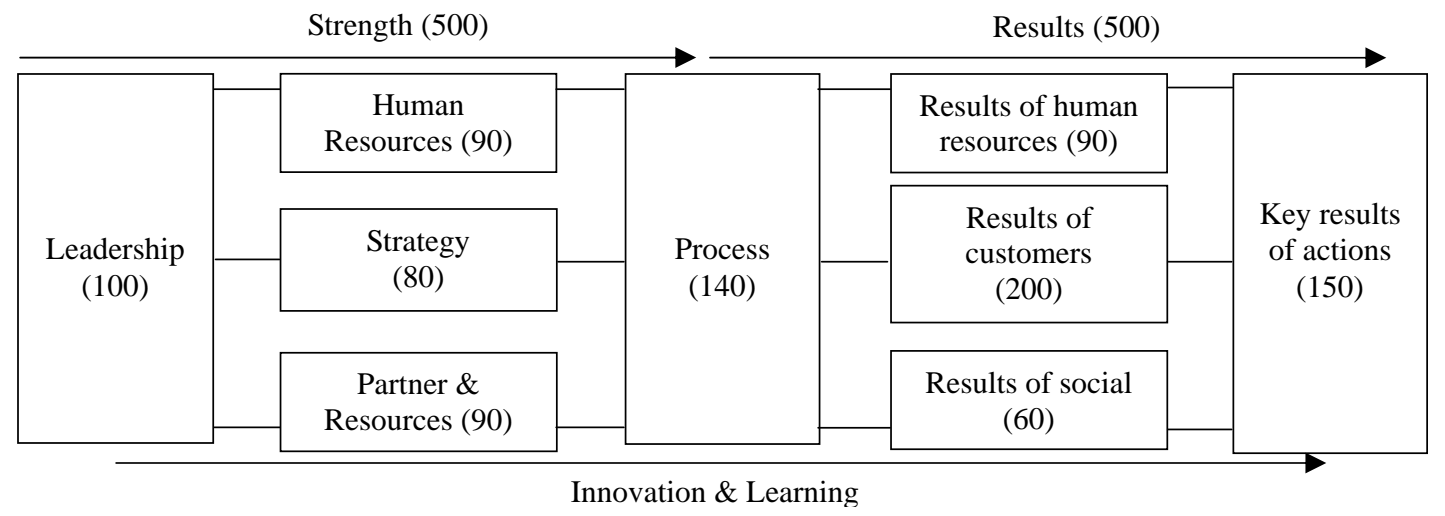

Fig. 1 Graphic model of EFQM

The excellence model of EFQM, like another award models such national quality award of Malcolm Baldrige in USA and Doming award in Japan have self-evaluation. The self-evaluation make for an order and expansive search and the organization results are because of model parameters (Hillman, 1994).

The researches show using of perfect in private organizations that is more success compare to universal parts of organizations (Asare \& Osseo, 2001). Currently, the members of England quality foundation have studied about this subject, and there are many advantages for their view point:

- Satisfaction and excitement of members;

- Strategy with more concentration and better;

- Conducting with more concentration and clearly;

- More clear and more brief of action programs (Bhatt, 2006).

\section{Iran national quality award (INQA)}

The profit national award and organized excellence in Iran have done as an effective instrument and for promoting the level of organizations management, confirmation of quality management systems, increase of profit and develop of organized excellence contexts with innovation of industrial and mine ministry since 2003. 
Whereas, the Iranian model of organized excellence is the same as the excellence model of EFQM in many aspects, and it is convergent to this model. The knowing of this model has challenges for administrators of organizations and Iran jobs like services, productions, education, etc.

It is hoped that using the experiment of this award may increase the culture of organized excellence in whole of companies in country (Najmi \& Hosseini, 2004).

The view of model is like a wheel, and plan as a symbol of movement. This model has 7 parameters. 4 parameters are forceful and 3 parameters are results. The first point of strength is in order, process parameters, resources and staff. 3 parameters of result are point of customer results and consumers that is a basic beneficiary of organization, the parameter of environment eco. result in industry financial and non-financial result and staff result are most important part of organization capitals.

The reasons of cycling force are innovational creativeness that make ability to learn across the start results, and it continuous with influence of learning in next cycle of innovation and creativeness. At all, the movement doesn't stop, if there were a power in leader parameter.

\section{Case study}

In 2008, the excellence model of EFQM used for evaluating of General Office of Standards and Industrial Research of Sistan and Baluchestan Province. It used one questionnaire include 50 close questions and same. Statistics social of this research were management, experts and customers. Statistical sample were about 50 person of above social which selected as informed.

The main method in this study was questionnaire method. The questionnaire used by an experimental way for evaluating different aspects of organizations that show the excellence of organization by ability and results of organization. In addition, in this research used technique of statistics deduction, because it seek proof or refutation of research theory, theories experiment and statistic deduction used related to them.

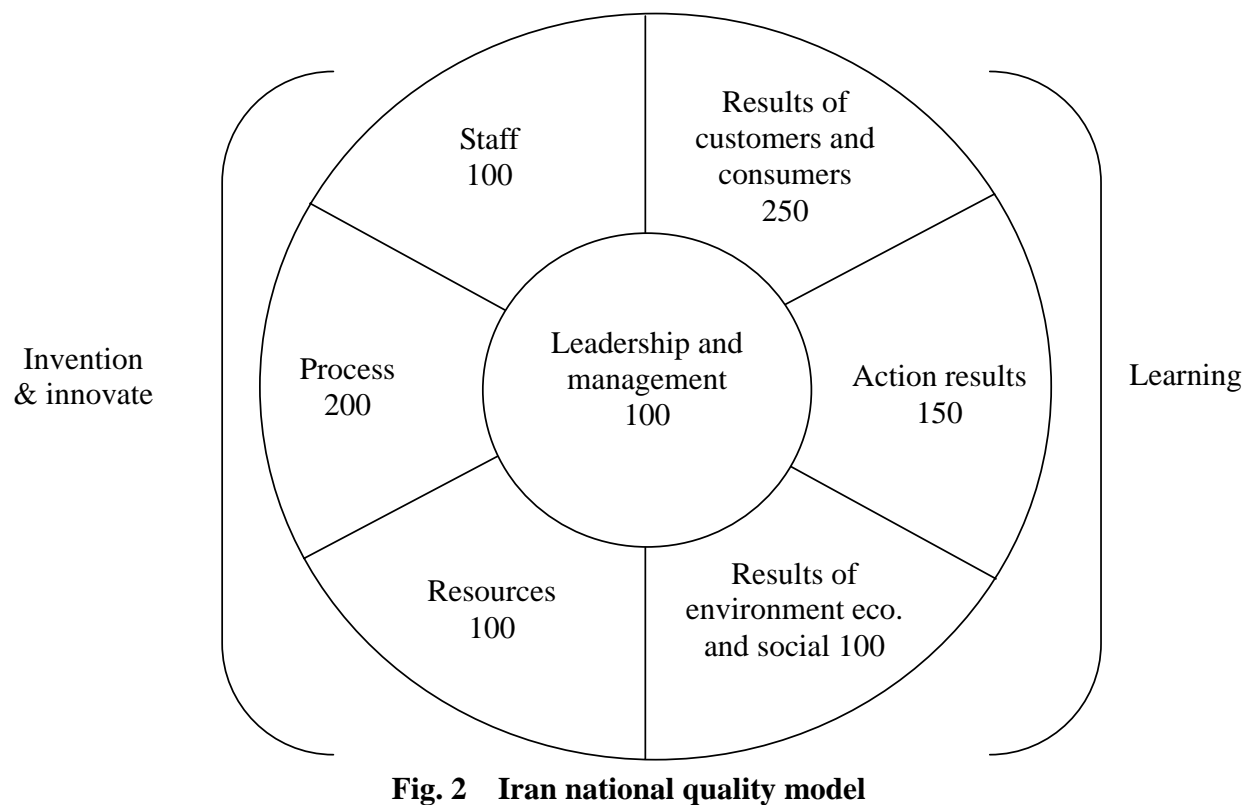

Fig. 2 Iran national quality model

Data source: www.inqa.org. 


\section{Results of study}

After evaluating of General Office of Standards and Industrial Research of Sistan and Baluchestan province by organization model EFQM, the researcher wanted one sample of statistic for completing the questioner of organization action evaluation according to the model of Iran national quality award, which is in "www.inqa.org" website (see Fig. 2). After that, the result of each evaluations aim like Table 1.

By comparing the result of EFQM model and INQA model and with attention of European model of EFQM by production process, the model of national quality award planned according to production process and final production.

Considerably, in European countries, the process regard by standards, but because of lack of perfect control and performance for standards in Iran, it should notice the final production.

Table 1 Compare the results of EFQM model and INQA model

\begin{tabular}{|c|c|c|c|c|c|}
\hline \multicolumn{2}{|c|}{ Scales } & \multicolumn{2}{|c|}{ Results of EFQM model } & \multicolumn{2}{|c|}{ Results of INQA model } \\
\hline EFQM scales & INQA scales & Distinction & $\begin{array}{l}\text { Percent of } \\
\text { distinction }\end{array}$ & Distinction & $\begin{array}{l}\text { Percent of } \\
\text { distinction }\end{array}$ \\
\hline Leadership & Leadership and & 60.20 & 60.20 & \multirow{2}{*}{50} & \multirow{2}{*}{50} \\
\hline Strategy & management & 50.76 & 63 & & \\
\hline Staff & Staff & 49.75 & 55 & 58.33 & 58.33 \\
\hline Partner \& Resources & Resources & 53.53 & 59 & 60 & 60 \\
\hline Process & Process & 81.32 & 58 & 112.5 & 56 \\
\hline Results of customers & Results of customers and & 123.91 & 62 & \multirow{2}{*}{128.9} & \multirow{2}{*}{52} \\
\hline Results of staff & consumers & 49.36 & 55 & & \\
\hline Key results of actions & Action results & 87.73 & 58 & 93.75 & 63 \\
\hline Results of social & $\begin{array}{l}\text { Results of environment } \\
\text { eco. and social }\end{array}$ & 36.64 & 61 & 12.5 & 12.5 \\
\hline \multicolumn{2}{|l|}{ Distinction of valuation } & 593.2 & & 515 & \\
\hline
\end{tabular}

\section{Conclusion}

The model of INQA has balances with Iranian organizations. It makes a chance for organizations that create a clear way for productions and develop process and resources for promoting quality. It also raises the staff ability for productions, and shows in focus to differences of evaluation results, using the model suggest for evaluating in Iran organizations.

\section{References:}

Assare, O.. (2002). The need education and training in the use of the EFQM model. Quality Assurance in Education, 10(1). Bhatt, D.. (2006). EFQM excellence model and KM implications. Total Quality Managemenr, 15(4).

Carlos, J.. (2003). To what extent do enablers explain results in the EFQM excellence model? International Journal of Quality \& Reliability Management, 22(4).

Hillman, G. P.. (1994). Making self-assessment successful. The EFQM Magazine, 6.

Khalili, M.. (2005). Organizational excellence models guide of firms performance progress. Retrieved from http://www.min.gov.ir. Najmi, M. \& Hosseini, S.. (2004). The EFQM excellence model from plan to act. Ronas.

Wongrassamee, S.. (2003). Performance measurement tools: The balanced scorecard and the EFQM excellence model. Measuring Business Excellence, 7(1). 